\title{
The use of a biphasic calcium phosphate in a maxillary sinus floor elevation procedure: a clinical, radiological, histological, and histomorphometric evaluation with 9- and 12-month healing times
}

\author{
W. F. Bouwman ${ }^{1,5}$ D, N. Bravenboer ${ }^{2}$, J. W. F. H. Frenken ${ }^{3}$, C. M. ten Bruggenkate ${ }^{1,4}$ and E. A. J. M. Schulten ${ }^{1 *}$
}

\begin{abstract}
Background: This study evaluates the clinical, radiological, histological, and histomorphometric aspects of a fully synthetic biphasic calcium phosphate (BCP) (60\% hydroxyapatite and 40\% ß-tricalcium phosphate), used in a human maxillary sinus floor elevation (MSFE) procedure with 9- and 12-month healing time.

Methods: A unilateral MSFE procedure, using 100\% BCP, was performed in two series of five patients with healing times of 9 and 12 months respectively. Clinical and radiological parameters were measured up to 5 years postoperatively. Biopsy retrieval was carried out during dental implants placement. Histology and histomorphometry were performed on 5 - $\mu$ m sections of undecalcified bone biopsies.

Results: The MSFE procedure with BCP showed uneventful healing in all cases. All dental implants appeared to be well osseointegrated after 3 months. Radiological evaluation showed less than $1 \mathrm{~mm}$ tissue height loss from MSFE to the 5year follow-up examination. No signs of inflammation were detected on histological examination. Newly formed mineralized tissue was found cranially from the native bone. The BCP particles were surrounded by connective tissue, osteoid islands, and newly formed bone. Mineralized bone tissue was in intimate contact with the BCP particles. After 12 months, remnants of BCP were still present. The newly formed bone had a trabecular structure. Bone maturation was demonstrated by the presence of lamellar bone. Histomorphometric analysis showed at 9 and 12 months respectively an average vital bone volume/total volume of 35.2 and 28 . $2 \%$, bone surface/total volume of $4.2 \mathrm{~mm}^{2} / \mathrm{mm}^{3}$ and $8.3 \mathrm{~mm}^{2} / \mathrm{mm}^{3}$, trabecular thickness of 224.7 and 66 . $7 \mu \mathrm{m}$, osteoid volume/bone volume of 8.8 and 3.4\%, osteoid surface/bone surface (OS/BS) of 42.4 and 8.2\%, and osteoid thickness of 93.9 and $13.6 \mu \mathrm{m}$.
\end{abstract}

Conclusions: MFSE with BCP resulted in new bone formation within the augmented sinus floor and allowed the osseointegration of dental implants in both groups. From a histological and histomorphometric perspective, a 9-month healing time for this type of BCP may be the optimal time for placement of dental implants.

Keywords: Biphasic calcium phosphate, Bone substitute, Sinus augmentation, Sinus floor elevation

\footnotetext{
* Correspondence: eajm.schulten@vumc.nl

${ }^{1}$ Department of Oral and Maxillofacial Surgery/Oral Pathology, VU University Medical Center/Academic Centre for Dentistry Amsterdam (ACTA), P.O. Box 7057, 1007 MB Amsterdam, The Netherlands

Full list of author information is available at the end of the article
} 


\section{Background}

Maxillary sinus floor elevation (MSFE) is a surgical procedure to enhance the bone height in the posterior maxilla with graft material, allowing dental implant placement (later or at the same time) $[1,2]$. This pre-implant procedure is predictable and results in a dental implant survival of more than $93.8 \% 3$ years after dental implant placement [3]. According to Pjetursson [4] in his systematic review on success of implants inserted in combination with sinus floor elevation, the implant survival increases to $98.3 \%$ after 3 years when compared to non-augmented jawbone.

Autogenous bone is still the gold standard, because of its osteoconductive and osteoinductive properties, due to the possible osteogenic capacity [5-10]. Moreover, the bone morphogenic proteins, present in autogenous bone grafts, can attract osteogenic cells from the surrounding tissues, in their turn containing other growth factors essential for the process of bone graft incorporation [4].

As the maxillary tuberosity, mandibular retromolar or chin region do not always supply enough bone graft volume, bone grafts can also be harvested from the anterior iliac crest, the tibia, the rib, and the calvarian bone. However, these harvesting procedures have disadvantages, such as prolonged operating time, donor site morbidity, hospitalization [9, 11-13], sensory disturbances [14], and unpredictable resorption rate of the bone grafts $[5,15]$. Donor site morbidity may be a major reason to question the use of autogenous bone [16]. Therefore, several types and properties of bone substitutes (alloplast, xenograft, allograft, and mixtures of various materials) have been developed [16, 17] to overcome the disadvantages mentioned above.

Calcium phosphates, such as hydroxyapatite (HA), $\beta$ tricalcium phosphate $(\beta-\mathrm{TCP})$, or biphasic calcium phosphate (BCP), a mixture of HA and $\beta$-TCP, are osteoconductive as they resemble the chemical composition of natural bone $[18,19]$. Calcium phosphates are biocompatible and do not induce a sustained foreign body response or toxic reaction [20]. At a physiological $\mathrm{pH}$, calcium phosphates are the least soluble of the naturally occurring calcium phosphates, which makes them relatively resistant to resorption [21-23].

$\beta$-TCP is a biocompatible osteoconductive calcium phosphate that may provide a scaffold for potential bony ingrowth [24]. $\beta$-TCP resorbs rather quickly but not necessarily at the same rate as new bone formation [25-27]. Most research focused on either using the relative unresorbable $\mathrm{HA}$ as a scaffold or $\beta$-TCP as a degradable component $[19,24-26,28,29]$. Zerbo et al. [30] concluded that due to the absence of osteoinductive properties of TCP, the rate of bone formation was delayed in comparison with autogenous bone grafts. It would be beneficial for the patient to reduce the interval between the MSFE procedure and dental implant placement to accelerate the process of integration of the grafted material. $\mathrm{BCP}$, in a combination of $60 \% \mathrm{HA}$ and $40 \% \beta$-tricalcium phosphate, demonstrated new bone formation in both animals and humans [24, 31-33]. This biphasic calcium phosphate (BCP) appeared to be a suitable graft material for vertical augmentation of the posterior maxilla by means of an MSFE procedure and dental implants placement in a study with a healing time of 6 months [16, 27, 34].The process of bone substitution may not be completed after 6 months of follow-up [27, 35]. Even though clinically, the tissue seems stable enough for dental implant placement, the high bone formation, especially in the newly formed bone areas, indicates that after 6 months, bone cells are still actively replacing BCP in vital bone tissue. To date, no long-term follow-up has been reported on the use of a synthetic BCP, consisting of $60 \% \mathrm{HA}$ and $40 \% \beta$-TCP, which may elucidate the degradation properties of BCP material. One may have to consider that more time is necessary to achieve a new bone balance. The aim of this study is to evaluate the clinical, radiological, histological, and histomorphometric aspects of a synthetic BCP (Straumann $^{\odot}$ Bone Ceramic, Institut Straumann AG, Basel Switzerland) that was used in a MSFE procedure with 9and 12-month healing times.

\section{Methods}

\section{Study population}

In this study, 10 consecutive healthy patients were selected for a unilateral MSFE procedure. Five patients received dental implants 9 months after MSFE and five patients underwent dental implant surgery 12 months after MSFE. In the 9-month group (three men and two women), the average age was 56.6 years (range 40 to 64 years); in the 12-month group (one man and four women), the average age was 58.2 years (range 51 to 67 years). All patients were partially edentulous in the posterior maxilla without the need for onlay bone grafting of the alveolar crest to achieve an adequate alveolar ridge. A minimal native bone height of $4 \mathrm{~mm}$ (calculated from measurements on a preoperative panoramic radiograph) was preferred in both study groups. All selected patients were non-smokers, showed no systemic disease, and were not drug users.

The study was performed in accordance with the principles of the Declaration of Helsinki. Since the study involved CE-marked devices (calcium phosphates) being used for their intended purpose (use as carrier material for bone augmentation in sinus floor elevation procedures) and the harvested material can be regarded as surgical waste, no specific regulatory approval from a medical ethical committee was required. Patients provided written consent before the study-related procedures were undertaken. The biopsies were retrieved during dental implant surgery by means of 
trephine drills, implicating the tissue in the hollow drill is considered surgical waste. For the patient, this is not an additional invasive procedure. The different healing times did not have a negative impact on the patients.

\section{Maxillary sinus floor elevation procedure}

Ten patients were scheduled for a unilateral two-stage MSFE top-hinge door lateral window technique procedure, as described by Tatum [2]. All 10 patients were treated in an outpatient procedure under local anesthesia. Perioperatively, all patients received an antibiotic profylaxis, consisting of amoxicillin $500 \mathrm{mg}$ four times daily for 7 days, starting 1 day before the MSFE procedure. An oral rinse with chloorhexidine-digluconate $0.12 \%$, three times, $10 \mathrm{~cm}^{3}$ daily for $1 \mathrm{~min}$ for 2 weeks was prescribed, as part of the standard protocol for an MSFE procedure.

A midcrestal incision was made with vertical release incisions at the canine and tuberosity region. A fullthickness mucoperiosteal flap was elevated. The lateral maxillary sinus wall was prepared using a diamond burr with copious irrigation with sterile isotonic saline, regarding the contour of the maxillary sinus as observed on the preoperative panoramic radiograph. A bony tophinge trap-door was mobilized and turned inward and upward into a horizontal position in the maxillary sinus, together with the carefully elevated Schneiderian membrane. The area created between the lifted lid and the sinus floor was filled only with BCP (Straumann ${ }^{\circ}$ Bone Ceramic). The BCP was $100 \%$ crystalline, highly pure, and had a porosity of $90 \%$. The pores were 100 to $500 \mu \mathrm{m}$ in diameter. No membrane was used to cover the lateral window [36]. Primary wound closure was performed with Gore-Tex ${ }^{\oplus}$ sutures (W.L. Gore \& Associates, Newark, DE, USA). Immediately after the procedure, a panoramic radiograph was made. Postoperative examination and removal of the sutures were performed 10 to 14 days after the MSFE procedure.

\section{Dental implant surgery and biopsy retrieval}

After 9-month (five patients) and 12-month (five patients) healing times, a crestal incision was made with small mesial and distal buccal vertical release incisions. Subsequently, a full-thickness mucoperiostal flap was raised. The alveolar ridge was inspected for suitable implant placement, and the former lateral window area was inspected for tissue condition. Implant preparations were made, and biopsies were obtained from the grafted area at planned dental implant positions using trephine drills with an external diameter of $3.5 \mathrm{~mm}$ and internal diameter of $2.5 \mathrm{~mm}$ (Straumann trephine drill) with copious irrigation of sterile saline. In the 10 patients, 22 standard plus, regular neck, soft tissue level Straumann ${ }^{\circ}$ SLA dental implants with a diameter of $4.1 \mathrm{~mm}$ and a length of 10 or $12 \mathrm{~mm}$ were placed (Fig. 1). The implants were left to integrate in a non-submerged unloaded fashion. Soft tissue closure was performed with Gore-Tex sutures. A postoperative radiological examination (panoramic radiograph) was taken directly after dental implantation. Sutures were removed after 10 to 14 days and, if needed, provisional prosthetics were adapted to the new situation. Attention was paid to prevent premature loading of the dental implants. The patients were instructed to avoid loading of the posterior maxilla upon which the operation had been conducted until the 3-month

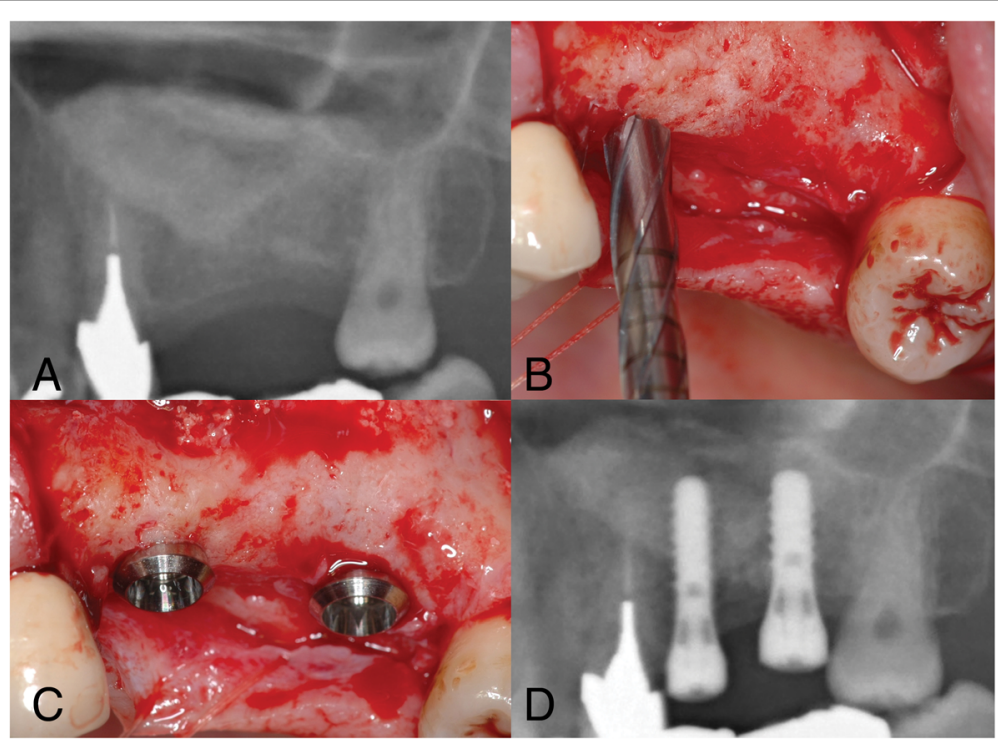

Fig. 1 Images of patient \# 5 (9-month healing time). a. Radiograph of the left maxillary sinus: situation 9 months after the maxillary sinus floor elevation procedure. $\mathbf{b}$. With a trephine drill, the implant osteotomy is made and the biopsy is obtained. c. Clinical situation after placing two Straumann ${ }^{\circledast}$ SLA implants in the left posterior maxilla. d. Radiograph of two Straumann ${ }^{\oplus}$ SLA implants in the left posterior maxilla 
integration time of the dental implants had passed and the fixed superstructures were fabricated and placed.

\section{Clinical evaluation}

All 22 inserted dental implants were clinically tested for good primary stability. Osseointegration at abutment connection was tested with a $35-\mathrm{Ncm}$ torque. One experienced oral and maxillofacial surgeon $(\mathrm{CB})$ carried out all follow-up examinations.

\section{Radiological evaluation}

Panoramic radiographs were made at patient's intake (T0); immediately after the MSFE procedure (T1); immediately after dental implant placement (T2); 1 year after dental implant placement (T3); and 5 years after dental implant placement (T4). On the panoramic radiographs, changes in tissue height $(\mathrm{mm})$ of the grafted area were measured at the implant site on the following time points: T0, T1, $\mathrm{T} 2$, T3, and T4. An average magnification of $\times 1.25$ was taken into account to calculate true tissue heights.

\section{Qualitative histological and quantitative histomorphometric analysis}

Bone biopsies were obtained during implant surgery as previously described [37]. Trephines were split and opened in order to secure the orientation of the biopsies. The biopsies were fixed overnight in $4 \%$ phosphatebuffered formaldehyde and transferred to alcohol $70 \%$ [38]. After dehydration, the bone specimens were embedded without prior decalcification in methylmethacrylate supplemented with $20 \%$ dibuthylphtalaat and $0.008 \mathrm{~g} / \mathrm{ml}$ Lucidol. The biopsies were cut into $5-\mu \mathrm{m}$ longitudinal sections (Polycut S., Leica microtome type sm2500s, Leica, Wetzlar, Germany). Bone mass indices and osteoid surface were measured in Goldner's trichrome stained sections [39]. Tartrate-resistant acid phosphate (TRAP) staining was performed to visualize osteoclasts. Measurements were performed semi-automatically using a digitizer and image analysis software (Osteomeasure, Atlanta, GA, USA). In this study, the Von Kossa staining was used to verify remnant particles of BCP (Straumann ${ }^{\circ}$ Bone Ceramic). $\mathrm{BCP}$ particles were detected semi-quantitatively by three independent observers and classified into quartiles ( $<25 \%$ of BCP, $>25 \%$ and $<50 \%$ of BCP, $>50<75 \%$ of BCP, $>75 \%$ of $\mathrm{BCP}$ ). Nomenclature was used according to the American Society for Bone and Mineral Research (ASBMR) nomenclature committee [40].

Since it was impossible to discriminate between resident and augmented bone, histomorphometric measurements were performed over the total section of the biopsy, including native and newly formed bone. The parameters were measured in consecutive fields of a complete section, in four $150-\mu \mathrm{m}$ separated sections throughout the biopsy, covering a total measured area of $60 \mathrm{~mm}^{2}$. The specimens were examined for the following parameters:

Parameters evaluating vital bone mass/bone structure:

1: Vital bone volume (BV): percentage of the grafted section that is vital bone tissue (\%)

2: Bone surface (BS): BS expressed as a fraction of the total vital bone volume $\left(\mathrm{mm}^{2} / \mathrm{mm}^{3}\right)$

3: Thickness of bone trabeculae (Tb.Th) $(\mu \mathrm{m})$

Parameters evaluating bone turnover:

1: Osteoid volume $(\mathrm{OV})$ : fraction of the vital bone tissue section that is osteoid (\%)

2: Osteoid surface (OS): osteoid-covered surfaces expressed as the fraction of the total BS (\%) to measure new vital bone formation

3: Osteoid thickness (O.Th) $(\mu \mathrm{m})$

4: Number of osteoclasts (N.Oc) per $\mathrm{mm}^{2}$ total area

\section{Statistical analysis}

Because of the observational nature of this study and the limited number of biopsies, only descriptive statistics are presented. Results are expressed as mean standard deviation.

\section{Results}

\section{Clinical evaluation}

None of the 10 patients showed postoperative inflammation or infection after the MSFE procedure nor during surgical re-entry for dental implant placement. When opening the area for dental implant insertion, the grafted area proved to be well vascularized and the tissue at the site of the former trap-door location was slightly flexible and had a fibrous aspect. Between the periosteum and the bone graft area, adhesions were seen. Macroscopically, no voids or presence of purulent discharge were observed. Although a demarcation was observed between the grafted area and the original bone of the alveolar process, there was continuity between the grafted area and the native bone. There was no jiggling of the drill, even though bone substitute particles could still be recognized in the tissue specimen retrieved. All particles appeared well integrated in newly formed tissue. These findings were consistent in all 10 patients. In total, 22 Straumann SLA solid screw (standard plus regular neck, soft tissue level) dental implants with a diameter of $4.1 \mathrm{~mm}$ and a length of 10 or $12 \mathrm{~mm}$ were placed. Primary stability was achieved with all dental implants. All dental implants osseointegrated well and could be loaded with fixed prostheses 3 months after implant surgery. No dental implants were lost during 5-year follow-up.

\section{Radiological evaluation}

The increase in height of the grafted area achieved by the MSFE procedure was on an average of $7.5 \mathrm{~mm}(\mathrm{SD} \pm 2.8)$ in the 9-month group (Table 1) and $9.3 \mathrm{~mm}(\mathrm{SD} \pm 3.1)$ in 
Table 1 Alveolar tissue height measurements on panoramic radiographs (in true $\mathrm{mm}$ ) in the 9-month group

\begin{tabular}{lllllllll}
\hline Patient & $\begin{array}{l}\text { Gender/ } \\
\text { age }\end{array}$ & $\begin{array}{l}\text { Implant } \\
\text { site }\end{array}$ & T0 & T1 & Increase & T2 & T3 & T4 \\
\hline 1 & F/54 & 15 & 5.4 & 15.2 & 9.8 & 14.0 & 13.6 & 13.2 \\
1 & F/54 & 16 & 5.7 & 14.3 & 8.6 & 14.6 & 13.0 & 13.5 \\
2 & M/62 & 16 & 5.5 & 15.1 & 9.6 & 13.2 & 12.4 & 12.4 \\
3 & F/64 & 15 & 7.0 & 15.2 & 8.2 & 13.4 & 12.8 & 12.2 \\
4 & M/63 & 26 & 6.0 & 11.7 & 5.7 & 14.7 & 14.8 & 14.6 \\
4 & M/63 & 27 & 10.0 & 11.3 & 1.3 & 14.8 & 13.5 & 13.4 \\
5 & M/40 & 26 & 4.1 & 12.3 & 8.2 & 12.4 & 12.0 & 12.5 \\
5 & M/40 & 27 & 7.3 & 16.3 & 9.0 & 15.5 & 14.3 & 13.8 \\
Mean & 56.6 & & 6.4 & 13.9 & 7.5 & 14.1 & 13.3 & 13.2 \\
SD & & & 1.7 & 1.9 & 2.8 & 1.0 & 0.9 & 0.8 \\
\hline
\end{tabular}

Age in years at biopsy retrieval; hard tissue height corrected for magnification $(\times 1.25)$ on panoramic radiograph

$M$ male, $F$ female, TO (native bone height) preoperative alveolar bone height, $T 1$ directly after MSFE procedure, $T 2$ immediately after dental implant placement, $T 3$ 1 year after dental implant placement, $T 45$ years after dental implant placement

the 12-month group (Table 2). The measured tissue height appeared to be stable between 1 and 5 years in the 9month group (Fig. 2) and the 12-month group (Fig. 3).

\section{Qualitative histological evaluation}

The histological evaluation was performed on the complete section, comprising native bone, newly formed

Table 2 Radiological results (alveolar tissue height measurements in true $\mathrm{mm}$ ) in the 12-month group

\begin{tabular}{lllllllll}
\hline Patient & Gender/age & Implant site & T0 & T1 & Increase & T2 & T3 & T4 \\
\hline 1 & F/53 & 15 & 6.3 & 17.6 & 11.3 & 18.7 & 17.4 & 17.4 \\
1 & F/53 & 16 & 2.5 & 17.6 & 15.1 & 17.9 & 16.4 & 15.9 \\
1 & $F / 53$ & 17 & 1.3 & 15.5 & 14.2 & 13.7 & 12.8 & 12.6 \\
2 & $F / 53$ & 26 & 8.8 & 17.2 & 8.4 & 16.7 & 16.1 & 17.0 \\
2 & $F / 53$ & 27 & 7.9 & 13.1 & 5.2 & 11.3 & 12.0 & 11.9 \\
3 & $F / 67$ & 14 & 4.2 & 13.4 & 9.2 & 14.1 & 14.0 & 14.0 \\
3 & $F / 67$ & 15 & 4.1 & 11.0 & 6.9 & 9.9 & 12.7 & 12.8 \\
3 & $F / 67$ & 16 & 5.6 & 9.9 & 4.3 & 9.0 & 11.4 & 11.0 \\
4 & M/67 & 14 & 2.5 & 13.9 & 11.4 & 13.8 & 13.3 & 14.1 \\
4 & M/67 & 15 & 3.0 & 12.2 & 9.2 & 12.5 & 11.2 & 11.8 \\
4 & M/67 & 17 & 4.3 & 10.7 & 6.4 & 10.5 & 10.1 & 10.3 \\
5 & $F / 51$ & 24 & 5.5 & 13.7 & 8.2 & 14.0 & 13.8 & 14.4 \\
5 & $F / 51$ & 25 & 2.5 & 13.0 & 10.5 & 14.6 & 13.6 & 13.2 \\
5 & $F / 51$ & 26 & 3.6 & 14.1 & 10.5 & 14.0 & 13.2 & 13.4 \\
Mean & 58.2 & & 4.4 & 13.8 & 9.3 & 13.6 & 13.4 & 13.5 \\
SD & & & 2.0 & 2.3 & 3.1 & 3.8 & 2.0 & 2.1 \\
\hline
\end{tabular}

Age in years at biopsy retrieval; hard tissue height corrected for magnification $(\times 1.25)$ on panoramic radiograph

$M$ male, $F$ female, TO (native bone height) preoperative alveolar bone height, $T 1$ after MSFE procedure, $T 2$ immediately after dental implant placement, $T 3$

1 year after dental implant placement, $T 45$ years after dental implant placement

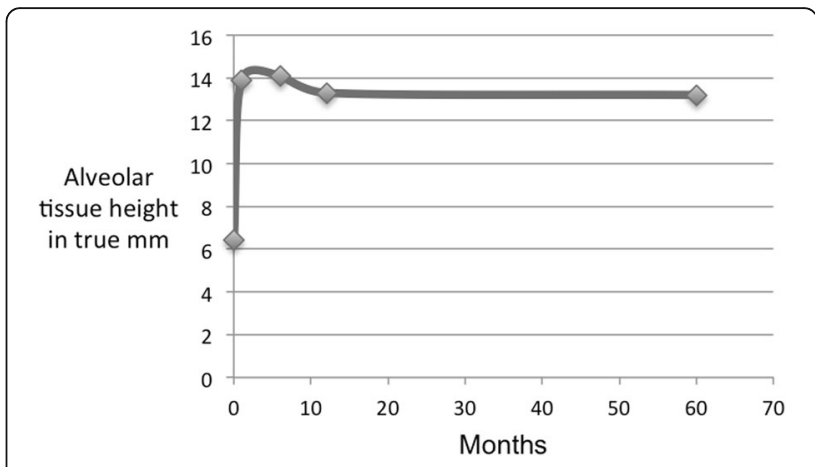

Fig. 2 Aveolar tissue height (in true $\mathrm{mm}$ ) over a 5-year period in the 9-month group

bone, and residual graft material. The BCP particles were surrounded by connective tissue, osteoid islands, and newly formed bone. From the residual bone in all specimens, new bone formation was detected following the scaffold of the bone substitute, starting in cranial direction. This newly formed bone consisted of woven bone as well as lamellar bone and appeared as vital bone tissue containing osteoblasts, osteoid covering the border, and osteocytes inside bone lacunae. Cranially, near the lifted trap-door, some osteoid islands with osteogenic activity were detected.

Histological observations did not show inflammatory cells in the tissue adjacent to the bone substitute particles. Bone marrow-like tissue, which included blood vessels, was observed in between the bone trabeculae (Fig. 4). Reinforcement by lamellar bone was shown in some areas after 9 and 12 months (Figs. 5 and 6). No Howship's lacunae could be detected on the characteristic outlines of the substitute particles. Fragments of the substitute particles were present in the sections of the 9month group and the 12-month group, as confirmed by Von Kossa staining. Regardless of the histological process, the contours of the bone substitute remnants were clearly detectable which enabled analyses.

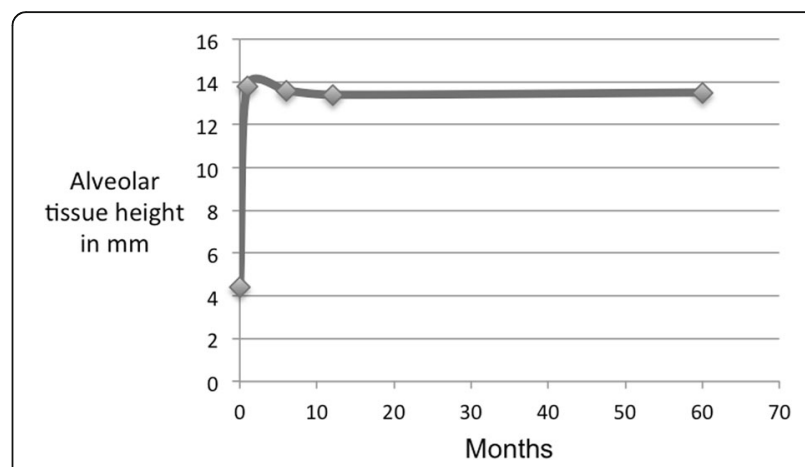

Fig. 3 Alveolar tissue height (in true $\mathrm{mm}$ ) over a 5-year period in the 12-month group 


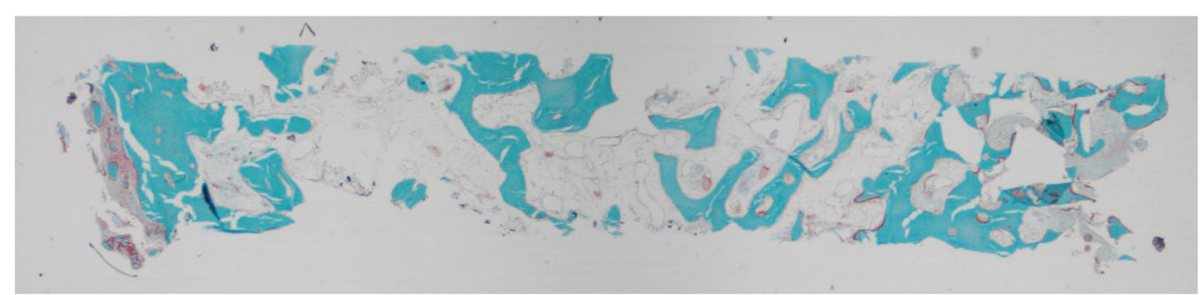

Fig. 4 Patient \# 1 (12-month healing time): overview of a typical example of a bone biopsy stained with Goldner trichrome staining (magnification $\times 10$ )

\section{Quantitative histomorphometric evaluation}

In the 9-month group, the average vital bone volume was $35.2 \%$ of the total biopsy volume (SD \pm 9.5 ) of which $8.8 \%$ (SD \pm 3.8 ) was osteoid. The osteoid surface covered $42.4 \%$ (SD \pm 12.1 ) of the bone surface. The BS covered $4.2 \mathrm{~mm}^{2} / \mathrm{mm}^{3}$ (SD \pm 1.9 ). In the total area for the 12-month group, the average vital bone volume was $28.2 \%$ of the total biopsy volume (SD $\pm 3.2)$ of which $3.4 \%(\mathrm{SD} \pm 2.5)$ was osteoid. The osteoid surface covered $8.2 \%(\mathrm{SD} \pm 5.3)$ of the bone surface. The BS covered $8.3 \mathrm{~mm}^{2} / \mathrm{mm}^{3}$ (SD \pm 1.3 ). In conclusion, vital bone volume and bone turnover decreased in the 12-month group compared to the 9month group. An overview of the individual histomorphometric findings is listed in Tables 3 and 4 .

\section{Discussion}

This study presents the clinical, radiological, histological and histomorphometric results on the use of a biphasic calcium phosphate (Straumann ${ }^{\circledR}$ bone ceramic) in a MSFE procedure with healing times of 9 and 12 months. During the clinical evaluation, it appeared that both 9-month and 12-month healing times resulted in integration of the grafted BCP with the original maxillary bone (sinus floor), which was

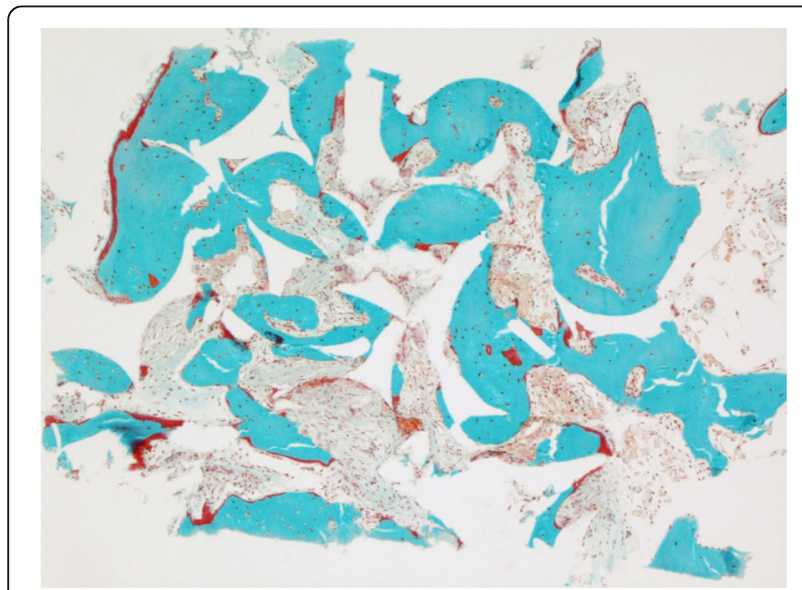

Fig. 5 Patient \# 4 (9-month healing time): increased bone formation following the shape of the grafted particles stained with Goldner trichrome staining (magnification $\times 100$ ) stable enough to ensure successful dental implant placement. It should be mentioned that in this study, a minimal native alveolar bone height of $4 \mathrm{~mm}$ was preferred, ensuring a certain primary stability of the dental implants placed. An adequate and stable tissue height in the grafted area was observed radiologically in a 5-year follow-up in all patients in both 9-month and 12-month healing time groups.

Radiological observations show very stable results in different healing times, in a previous 6-month study [27] and after 9- and 12-month healing times in the present study. However, this does not reveal the actual vital bone height available for attachment to the dental implant surface. This can only be measured by histological investigations. Reviews show that the loss of dental implants with an intra-osseous length of $8 \mathrm{~mm}$ or more, placed in native bone, is minimal [4]. Previously, the histomorphometrical and histological evaluation, 6 months after an MSFE procedure, using Straumann ${ }^{\circledR}$ bone ceramic was reported with a 1-year follow-up. At that time, no loss of dental implants was reported. In the present study, none of the implants in the 9- and 12-month groups were lost. Histological investigation showed that mineralized bone tissue was observed to be in intimate contact with the bone substitute particles, indicating that the graft

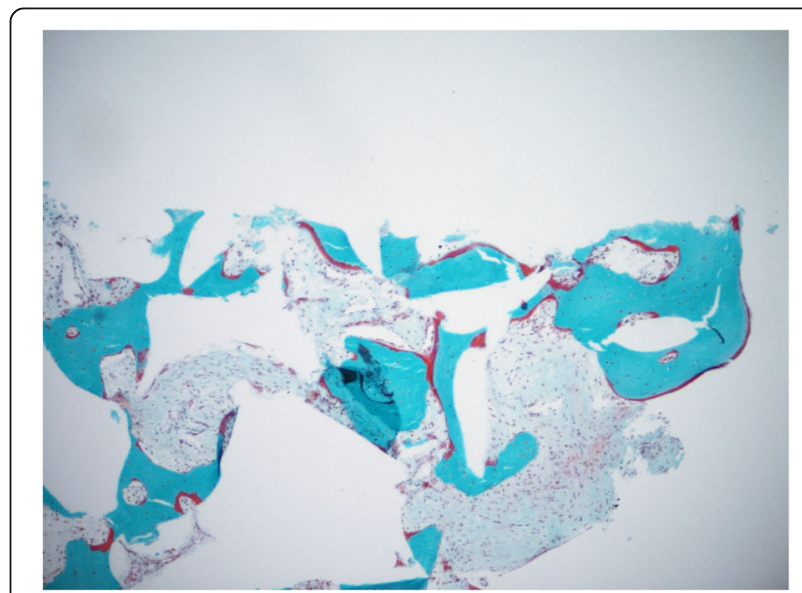

Fig. 6 Patient \# 1 (12-month healing time): increased bone formation following the shape of the grafted particles that are still present (magnification $\times 100$ ) 
Table 3 Histomorphometric evaluation of the biopsies after a 9-month healing time

\begin{tabular}{llllllllll}
\hline Patient $(N)$ & Gender/age) & Retrieval location & BV/TV (\%) & BS/TV $\left(\mathrm{mm}^{2} / \mathrm{mm}^{3}\right)$ & Tb.Th $(\mu \mathrm{m})$ & OV/BV $(\%)$ & OS/BS $(\%)$ & O.Th $(\mu \mathrm{m})$ & $\mathrm{N} . \mathrm{Oc} / \mathrm{Tar}\left(1 / \mathrm{mm}^{2}\right)$ \\
\hline 1 & $\mathrm{~F} / 54$ & 15 & 51.3 & 2.3 & 461.3 & 5.4 & 43.4 & 28.3 & 0.8 \\
2 & M/62 & 16 & 30.4 & 2.2 & 278.6 & 13.3 & 53.3 & 331.8 & 2.0 \\
3 & $\mathrm{~F} / 64$ & 15 & 29.3 & 4.6 & 121.7 & 8.5 & 50.0 & 10.2 & 2.5 \\
4 & M/63 & 27 & 36.3 & 5.8 & 168.8 & 4.7 & 22.3 & 18.8 & 2.3 \\
5 & M/40 & 26 & 28.5 & 6.2 & 93.0 & 12.0 & 43.0 & 80.2 & 5.0 \\
Mean & & & 35.2 & 4.2 & 224.7 & 8.8 & 42.4 & 93.9 & 2.5 \\
SD & & 9.5 & 1.9 & 150.0 & 3.8 & 12.1 & 135.8 & 1.5 \\
\hline
\end{tabular}

Not intact biopsies were excluded from histomorphometric examination. Age in years at biopsy retrieval

$M$ male, $F$ female, BV/TV vital bone volume/total volume, BS/TV bone surface/total volume, $T b . T h$ trabeculae thickness, OV/BV osteoid volume/vital bone volume, OS/BS osteoid surface/bone surface, O.Th osteoid thickness, N.Oc/Tar number of osteoclasts in total area

material possesses osteoconductive properties [27] (which is in agreement with other observations) $[16,24,34]$. This positive effect might be explained by its chemical composition. BCP materials have shown bone formation simultaneously with material degradation $[24,25]$. BCP exhibited moderate signs of substitute degradation in humans not only after 6 months, as previously reported by Frenken et al. [27]. The present study still observed remnants of BCP after 9 and 12 months which suggests that the ossification rate is not the same as the resorption rate of the BCP. Because osteoclasts were detected next to the characteristic outlines of the substitute particles, it is suggested that $\mathrm{BCP}$ is resorbed by osteoclasts. The high bone formation in the newly formed bone area indicates that after 12 months, bone cells are still actively forming new bone matrix, thereby absorbing and replacing $\mathrm{BCP}$ in vital bone tissue.

In the cranial part of the biopsy, some osteoid islands with osteogenic activity were detected, possibly caused by osteoinductive properties from the lifted bony trapdoor. In the present study, histomorphometric analyses revealed that the vital bone volume was higher in the 9month healing time group than in the 12-month healing time group, while one would expect to find more newly formed bone in time as more of the bone substitute resorbs. As the mean original native alveolar bone height is $6.4 \mathrm{~mm}$ in the 9-month group and $4.4 \mathrm{~mm}$ in the 12 - month group and augmented portion of the 12-month group $(9.3 \mathrm{~mm})$ is higher than the 9-month group $(7.5 \mathrm{~mm})$, this may have a negative impact on the relatively smaller portion of the bone volume of the total biopsy in the 12-month group. This is a limitation of the present study.

However, the average $2 \mathrm{~mm}$ of difference in the native bone height between the 9- and 12-month groups does not fully explain the difference in BT/TV that was found between the two groups. Furthermore, the thickness of the bone trabeculae decreased suggesting that at 12 months, bone turnover returns to a relatively normal bone remodeling status, indicative of a new balance in bone tissue. However, woven bone (data not shown) and the remnants of the BCP were still present at 12 months, contradicting this hypothesis. Nevertheless, from a histological and histomorphometric perspective in the present study, a 9-month healing time may be the optimal time for the placement of dental implants. Although the sample size of the two groups is small, multiple dental implant placements deliver sufficient data for evaluation. The 12-month period from MSFE to implant placement(s) is considered to be a long time. Most patients are not willing to wait that long, which makes these bone samples very scarce and therefore valuable for long-term observations. The implication of the small sample size is that this study has an

Table 4 Histomorphometric evaluation of the biopsies after a 12-month healing time

\begin{tabular}{lllllllll}
\hline Patient $(N)$ & Gender/age & Retrieval location & BV/TV $(\%)$ & BS/TV $\left(\mathrm{mm}^{2} / \mathrm{mm}^{3}\right)$ & Tb.Th $(\mu \mathrm{m})$ & OV/BV $(\%)$ & OS/BS $(\%)$ & O.Th $(\mu \mathrm{m})$ \\
\hline 1 & F/53 & 16 & 25.5 & 6.9 & 74.1 & 1.7 & 5.2 & 12.8 \\
2 & F/53 & 25 & 30.8 & 9.2 & 66.8 & 1.1 & 3.1 & 12.7 \\
2 & F/53 & 26 & 29.3 & 9.5 & 61.5 & 4.2 & 9.2 & 14.7 \\
3 & M/67 & 17 & 24.0 & 7.5 & 64.4 & 6.6 & 15.2 & 14.0 \\
Mean & & 28.2 & 8.3 & 66.7 & 3.4 & 8.2 & 13.6 \\
SD & & 3.2 & 1.3 & 5.4 & 2.5 & 5.3 & 1 \\
\hline
\end{tabular}

Not intact biopsies were excluded from histomorphometric examination. Age in years at biopsy retrieval

$M$ male, $F$ female, $B V / T V$ vital bone volume/total volume, $B S / T V$ bone surface/total volume, Tb.Th trabeculae thickness, OV/BV osteoid volume/vital bone volume, $O S / B S$ osteoid surface/bone surface, O.Th osteoid thickness, NOc/BPm not measured as an insignificant number of osteoclasts were available 
observational nature and, therefore, only descriptive statistics are presented.

\section{Conclusions}

Based on clinical, radiological, histological, and histomorphometric analysis, this study confirms the suitability of $\mathrm{BCP}$ for vertical augmentation of the posterior maxilla by means of an MSFE procedure, allowing dental implant placement after 9 and 12 months healing times. Yet, complete degradation of the BCP particles does not occur within a 12-month healing time. From a histological and histomorphometric perspective, a 9-month healing time for this type of BCP may be the optimal time for the placement of dental implants.

\section{Authors' contributions}

WB contributed to the data acquisition, data analysis, and writing of the manuscript. BS and CB contributed to the design of the study and critical reading of the manuscript and have given final approval of the manuscript. NB contributed to the design of the study, data analysis, and critical reading of the manuscript. JF contributed to the data acquisition. All authors read and approved the final manuscript.

\section{Competing interests}

Authors W.F. Bouwman, N. Bravenboer, J.W.F.H. Frenken, C.M. ten Bruggenkate and E.A.J.M. Schulten state that there are no conflicts of interest, either directly or indirectly.

\section{Publisher's Note}

Springer Nature remains neutral with regard to jurisdictional claims in published maps and institutional affiliations.

\section{Author details}

${ }^{1}$ Department of Oral and Maxillofacial Surgery/Oral Pathology, VU University Medical Center/Academic Centre for Dentistry Amsterdam (ACTA), P.O. Box 7057, 1007 MB Amsterdam, The Netherlands. ${ }^{2}$ Department of Clinical Chemistry, VU University Medical Center, Amsterdam, The Netherlands. ${ }^{3}$ Department of Oral and Maxillofacial Surgery, St. Antonius Hospital, Nieuwegein, The Netherlands. ${ }^{4}$ Department of Oral and Maxillofacial Surgery, Alrijne Hospital, Leiderdorp, The Netherlands. ${ }^{5}$ Department of Oral and Maxillofacial Surgery, The Tergooi Hospital, Blaricum, The Netherlands.

Received: 22 May 2017 Accepted: 13 July 2017

Published online: 25 July 2017

\section{References}

1. Boyne PJ, James RA. Grafting of the maxillary sinus floor with autogenous marrow and bone. J Oral Surg. 1980;38:613-6.

2. Tatum H Jr. Maxillary and sinus implant reconstructions. Dent Clin N Am. 1986;30:207-29.

3. Del Fabbro M, Rosano G, Taschieri S. Implant survival rates after maxillary sinus augmentation. Eur J Oral Sci. 2008;116:497-506.

4. Pjetursson BE, Tan WC, Zwahlen M, Lang NP. A systematic review of the success of sinus floor elevation and survival of implants inserted in combination with sinus floor elevation. Part I: lateral approach. J Clin Periodontol. 2008:35:216-40.

5. Burchardt H. The biology of bone graft repair. Clin Orthop Relat Res. 1983; 174:28-42.

6. Jensen OT, Shulman LB, Block MS, lacono VJ. Report of the sinus consensus conference of 1996. Int J Oral Maxillofac Implants. 1998;13(Suppl):11-45.

7. Tong DC, Rioux K, Drangsholt M, Beirne OR. A review of survival rates for implants placed in grafted maxillary sinuses using meta-analysis. Int J Oral Maxillofac Implants. 1998;13:175-82

8. van den Bergh JP, ten Bruggenkate CM, Krekeler G, Tuinzing DB. Sinusfloor elevation and grafting with autogenous iliac crest bone. Clin Oral Implants Res. 1998;9:429-35.
9. Klijn RJ, Meijer GJ, Bronkhorst EM, Jansen JA. A meta-analysis of histomorphometric results and graft healing time of various biomaterials compared to autologous bone used as sinus floor augmentation material in humans. Tissue Eng Part B Rev. 2010;16:493-507.

10. Misch CM. Autogenous bone: is it still the gold standard? Implant Dent. 2010;19(5):361.

11. Kalk WW, Raghoebar GM, Jansma J, Boering G. Morbidity from iliac crest bone harvesting. Int J Oral Maxillofac Surg. 1996;54:1424-9.

12. Raghoebar GM, Louwerse C, Kalk WW, Vissink A. Morbidity of chin bone harvesting. Clin Oral Implants Res. 2001;12:503-7.

13. Zijderveld SA, ten Bruggenkate CM, van Den Bergh JP, EAJM S. Fractures of the iliac crest after split-thickness bone grafting for preprosthetic surgery: report of 3 cases and review of the literature. J Oral Maxillofac Surg. 2004;7:781-6.

14. Beirne JC, Barry HJ, Brady FA, Morris VB. Donor site morbidity of the anterior iliac crest following cancellous bone harvest. Int J Oral Maxillofac Surg. 1996; 25:268-71.

15. Vermeeren JJJF, Wismeijer D, van Waas MAJ. One-step reconstruction of the severely resorbed mandible with onlay bone grafts and endosteal implants: a 5-year follow-up. Int J Oral Maxillofac Surg. 1996:2:112-5.

16. Nkenke E, Stelzle F. Clinical outcomes of sinus floor augmentation for implant placement using autogenous bone or bone substitutes: a systematic review. Clin Oral Implants Res. 2009;20(Suppl. 4):124-33.

17. Wheeler SL. Sinus augmentation for dental implants: the use of alloplastic materials. J Oral Maxillofac Surg. 1997;55:1287-93.

18. Nery EB, Lee KK, Czajkowski S, Dooner JJ, Duggan M, Ellinger RF, Henkin JM, Hines R, Miller M, Olson JW. A veterans administration cooperative study of biphasic calcium phosphate ceramic in periodontal osseous defects. J Periodontol. 1990;61:737-44.

19. Zerbo IR, Bronckers AL, de Lange G, Burger EH. Localisation of osteogenic and osteoclastic cells in porous beta-tricalcium phosphate particles used for human maxillary sinus floor elevation. Biomaterials. 2005;26:1445-51.

20. Joosten $U$, Joist A, Frebel T, Walter M, Langer $M$. The use of an in situ curing hydroxyapatite cement as an alternative to bone graft following removal of enchondroma of the hand. J Hand Surg Br Eur. 2000;25(3):288-91.

21. Costantino PD, Friedman CD, Jones K, Chow LC, Pelzer HJ, Sisson GAS. Hydroxyapatite cement: I. Basic chemistry and histologic properties. Arch Otolaryngol Head Neck Surg. 1991;117:397-84.

22. Costantino PD, Friedman CD. Synthetic bone graft substitutes. Otolaryngolic Clin North Am. 1994;27:1037-74.

23. Jensen SS, Aaboe M, Pinholt EM, Hjorting-Hansen E, Melsen F, Ruyter IE. Tissue reaction and material characteristics of four bone substitutes. Int J Oral Maxillofac Implants. 1996;11:55-66.

24. Daculsi G, Laboux O, Malard O. Weiss P. Current state of the art of biphasic calcium phosphate bioceramics. J Mater Sci Mater Med 2003;14: 195-200.

25. LeGeros RZ, Lin S, Rohanizadeh R, Mijares D, LeGeros JP. Biphasic calcium phosphate bioceramics: preparation, properties and applications. J Mater Sci Mater Med. 2003:14:201-9.

26. Schopper C, Ziya-Ghazvini F, Goriwoda W, Moser D, Wanschitz F, Spassova E, Lagogiannis G, Auterith A, Ewers R. HAVTCP compounding of a porous CaP biomaterial improves bone formation and scaffold degradation-a long-term histological study. J Biomed Mater Res B Appl Biomater. 2005;74:458-67.

27. Frenken JW, Bouwman WF, Bravenboer N, Zijderveld SA, Schulten EA, ten Bruggenkate CM. The use of Straumann ${ }^{\oplus}$ Bone Ceramic in a maxillary sinus floor elevation procedure: a clinical, radiological, histological and histomorphometric evaluation with a 6-month healing period. Clin Oral Implants Res. 2010;21:201-8.

28. Bodde EW, Wolke JG, Kowalski RS, Jansen JA. Bone regeneration of porous betatricalcium phosphate (Conduit TCP) and of biphasic calcium phosphate ceramic (Biosel) in trabecular defects in sheep. J Biomed Mater Res. 2007;A 82:711-22.

29. Cordaro L, Bosshardt DD, Palattella P, Rao W, Serino G, Chiapasco M. Maxillary sinus grafting with Bio-Osss or Straumanns Bone Ceramic: histomorphometric results from a randomized controlled multicenter clinical trial. Clin Oral Implants Res. 2008;19:796-803.

30. Zerbo IR, Zijderveld SA, de Boer A, Bronckers AL, de Lange $G$, ten Bruggenkate $\mathrm{CM}$, Burger $\mathrm{EH}$. Histomorphometry of human sinus floor augmentation using a porous beta-tricalcium phosphate: a prospective study. Clin Oral Implants Res. 2004;15:724-32.

31. Nery EB, LeGeros RZ, Lynch KL, Lee K. Tissue response to biphasic calcium phosphate ceramic with different ratios of HA/beta TCP in periodontal osseous defects. J Periodontol. 1992;63:729-35. 
32. Boix D, Gauthier O, Guicheux J, Pilet P, Weiss P, Grimandi G, Daculsi G. Alveolar bone regeneration for immediate implant placement using an injectable bone substitute: an experimental study in dogs. J Periodontol. 2004;75:663-71.

33. Jensen SS, Yeo A, Dard M, Hunziker E, Schenk R. Buser D. Evaluation of a novel biphasic calcium phosphate in standardized bone defects. A

histologic and histomorphometric study in the mandibles of minipigs. Clin Oral Implants Res 2007;18: 752-760.

34. Klijn RJ, Hoekstra JWM, Van Den Beucken JJJP, Meijer GJ, Jansen JA. Maxillary sinus augmentation with microstructured tricalcium phosphate ceramic in sheep. Clin Oral Implants Res. 2012;23:274-80.

35. Groeneveld EH, van den Bergh JP, Holzmann P, ten Bruggenkate CM, Tuinzing DB, Burger EH. Mineralization processes in demineralized bone matrix grafts in human maxillary sinus floor elevations. J Biomed Mater Res. 1999:48:393-402

36. Schulten EAJM, Prins HJ, Overman JR, Helder MN, ten Bruggenkate CM, Klein-Nulend JA. Novel approach revealing the effect of collagenous membrane on osteoconduction in maxillary sinus floor elevation with $\beta$ tricalcium phosphate. Eur Cells Mater. 2013;25:215-28.

37. Oostlander AE, Bravenboer N, Sohl E, Holzmann PJ, van der Woude CJ, Dijkstra G, Stokkers PC, Oldenburg B, Netelenbos JC, Hommes DW, van Bodegraven AA, Lips P, Dutch Initiative on Crohn and Colitis (ICC). Histomorphometric analysis reveals reduced bone mass and bone formation in patients with quiescent Crohn's disease. Gastroenterology. 2011;140(1):116-23. Epub 2010 Sep 18

38. Schenk RK, Olah AJ, Herrmann W. Preparation of calcified tissues for light microscopy. In Methods of calcified tissue preparation. Dickson GR, editor. Amsterdam: Elsevier Science Publishers B.V.; 1984;1-56.

39. Romeis B. Trichromfaerbung nach Goldner, Mikroskopische Technik. Muenchen: Urban \& Schwarzenberg; 1989.

40. Dempster DW, Compston JE, Drezner MK, Glorieux FH, Kanis JA, Malluche H, Meunier PJ, Ott SM, Recker RR, Parfitt AM. Standardized nomenclature, symbols, and units for bone histomorphometry: a 2012 update of the report of the ASBMR Histomorphometry Nomenclature Committee. Journal of Bone and Mineral Research. 2012;DOI: 10.1002/jbmr.180.

\section{Submit your manuscript to a SpringerOpen ${ }^{\circ}$ journal and benefit from:}

- Convenient online submission

- Rigorous peer review

Open access: articles freely available online

- High visibility within the field

Retaining the copyright to your article

Submit your next manuscript at $>$ springeropen.com 